\title{
PIBID: DIVISOR DE ÁGUAS NO CURSO DE LICENCIATURA EM MATEMÁTICADO IFCE - CAMPUS CRATEÚS E NA FORMAÇÃO PROFISSIONAL DOS DOCENTES NOS SERTÕES DE CRATEÚS
}

\author{
Oscar Soares Araújo Júnior ${ }^{1}$, Antonio Avelar Macedo Neri², Antonia Dália Chagas Gomes ${ }^{3}$, \\ Renata Dutra de Quadro Silva ${ }^{4}$ \\ ${ }^{1}$ Secretaria de Educação do Ceará (SEDUC-CE) \\ ${ }^{2,3,4}$ Instituto Federal de Educação, Ciência e Tecnologia do Ceará (IFCE) \\ <oscarjunior.math@hotmail.com><avelarmacedo5@gmail.com> \\ <daliagomes.dg@gmail.com><rendutra215@hotmail.com>
}

DOI: $10.21439 /$ conexoes.v13i1.1563

\begin{abstract}
Resumo. O curso de Licenciatura em Matemática do IFCE, nos Sertões de Crateús, nasce para tentar suprir inúmeras lacunas educacionais, em especial no que se refere à formação de professores, que segundo o INEP (2004) dos 48.717 matriculados, apenas 8.740 concluíram; e a qualidade do ensino é bastante comprometida. Segundo os documentos normativos do curso, a licenciatura tem como objetivo formar profissionais competentes para o magistério, em especial na educação básica. Numa construção permanente, alinhando os conhecimentos científicos ao exercício da cidadania. Nessa tríade: acesso, permanência e profissionalização; resolvemos investigar se o Programa (PIBID), enquanto política pública contribui para quê os envolvidos no programa tenham tido êxito enquanto acadêmico e posteriormente como (inserção) profissional no magistério. A investigação proposta é de cunho quali-quantitativa e teve início com estudos sobre formação de professores, políticas públicas (PIBID), dados dos estudantes e concludentes do curso de matemática ao longo dos últimos 5 anos, e posteriormente sua inserção no mercado de trabalho. Após realizada a pesquisa de campo, constatamos que o programa, é determinante para a permanência, conclusão/ formação e profissionalização docente.
\end{abstract}

Palavras-chave: Formação de professores. Matemática. Profissionalização. Sertões.

\section{PIBID: WATER DIVIDER IN THE MECHANICS COURSE IN THE MATHEMATICS OF THE IFCE-CAMPUS CRATEUS AND IN THE PROFESSIONAL TRAINING OF TEACHERS IN THE SERATONS OF CRATEÚS}

\begin{abstract}
The IFCE Mathematics Degree course in the Sertões de Crateús was born to try to fill a number of educational gaps, especially with regard to teacher training, which according to INEP (2004) of the 48,717 enrolled, only 8,740 concluded; and the quality of teaching is greatly compromised. According to the normative documents of the course, the degree aims to train professionals competent to the teaching profession, especially in basic education. In a permanent construction, aligning scientific knowledge with the exercise of citizenship. In this triad: access, permanence and professionalization; we decided to investigate whether the Program (PIBID), as a public policy, contributes to the success of the program as an academic and then as a professional (insertion) in the teaching profession. The proposed research is qualitativequantitative and began with studies on teacher education, public policies (PIBID), data from students and conclusions of the math course over the last 5 years, and subsequently their insertion in the labor market. After conducting the field research, we verified that the program is determinant for the permanence, completion / formation and teacher professionalization.
\end{abstract}

Keywords: Teacher training. Mathematics. Professionalism. backlands. 


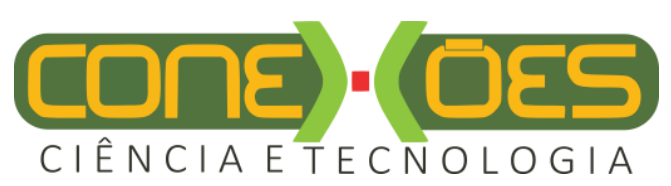

\section{INTRODUÇÃO}

A presente pesquisa é uma investigação que circunda os aspectos relacionados à temática das políticas públicas em educação, em especial, aquelas ligadas à formação inicial docente. Segundo Flores (2010) "uma das finalidades da formação inicial é a de preparar os futuros professores para trabalharem em escolas em contextos de mudança, o que implica uma reflexão permanente sobre o papel do professor" (p. 2). Nesse contexto, temos o Programa Institucional de Bolsas de Iniciação a Docência (PIBID) como política pública que visa dar suporte a formação inicial dos professores.

O programa teve início no ano de 2007, foi liberado pelo decreto $\mathrm{n}^{\circ} 2.219$, de 24 de junho de 2010 como uma ação conjunta entre Secretaria de Educação Superior (SESU) o Ministério da Educação (MEC) e a Coordenação de Aperfeiçoamento de Pessoal de Nível Superior (CAPES). Os objetivos do PIBID são cinco:

\footnotetext{
I) incentivar a formação de professores para a educação básica, apoiando os estudantes que optam pela carreira docente; valorizar o magistério, contribuindo para a elevação da qualidade da escola pública;

II) elevar a qualidade das ações acadêmicas voltadas à formação inicial de professores nos cursos de licenciatura das instituições de educação superior;

III) inserir os licenciandos no cotidiano de escolas da rede pública de educação, promovendo a integração entre educação superior e educação básica;

IV) proporcionar aos futuros professores participação em experiências metodológicas, tecnológicas e práticas docentes de caráter inovador e interdisciplinar e que busquem a superação de problemas identificados no processo de ensino-aprendizagem, levando em consideração o desempenho da escola em avaliações nacionais, como Provinha Brasil, Prova Brasil, SAEB, ENEM, entre outras;

V) incentivar escolas públicas de educação básica, tornando-as protagonistas nos processos formativos dos estudantes das licenciaturas, mobilizando seus professores como coformadores dos futuros docentes. (Portaria $\mathrm{n}^{\mathrm{o}}$ 72/2010).
}

Visamos contribuir para uma melhor compreensão do processo de materialização das políticas públicas em ações formativas concretas.

Neste contexto o PIBID, será objeto de estudo, tendo como eixo o seu fortalecimento da política pública de formação docente no IFCE - Campus Crateús. Nessa trajetória, faz-se necessário compreender que:

\begin{abstract}
A formação inicial e continuada do professor exige que o parque de universidades públicas se volte (e não que dê as costas) para a educação básica. Assim, a melhoria da qualidade da educação básica depende da formação de seus professores, o que decorre diretamente das oportunidades oferecidas aos docentes. O aprimoramento do nível superior, por sua vez, está associado à capacidade de receber egressos do nível básico mais bem preparados, fechando um ciclo de dependência mútua, evidente e positiva entre níveis educacionais (BRASIL, 2007, p. 9).
\end{abstract}

Ainda sobre essa preocupação governamental, destacamos a recente política pública criada para a formação docente: $O$ Programa Institucional de Bolsas de Iniciação à Docência (PIBID) oferece bolsas de iniciação à docência aos alunos de cursos de Licenciatura presenciais que se dediquem ao trabalho nas escolas públicas e que, quando graduados, comprometam-se com o exercício do magistério na rede pública. O objetivo é antecipar o vínculo entre os futuros mestres e as salas de aula da rede pública. Com essa iniciativa, o PIBID faz uma articulação entre a educação superior (por meio das licenciaturas), a escola e os sistemas estaduais e municipais. Diante desse quadro nacional, adiante, enfatizaremos o PIBID como forma de intervenção: socioeducativa, que visa a uma aproximação institucional entre Universidade e Escola Básica.

O PIBID tem sido, recentemente, tema de pesquisas locais (EIE, 2010) e nacionais (ENDIPE, 2010), as quais sugerem que esse programa pode auxiliar na formação docente. Por exemplo, AguiarJr. (2010) afirma que as políticas públicas em formação docente devem indicar novas práticas, estratégias e conteúdos de formação em diálogo com as escolas básicas. Para o autor, "o PIBID, Programa de Iniciação à Docência, financiado pela CAPES pode ser uma oportunidade ímpar nessa direção" (p. 260).

Nessa perspectiva, nos detemos nesta pesquisa ao estudo de aspectos da formação inicial e profissional no curso de licenciatura em matemática do IFCE, Campus Crateús, bem como, sua relação direta com o programa, analisaremos: a matrícula inicial no curso de licenciatura em matemática, a participação no PIBID como (ID), o número de concludentes e a inserção no mercado de trabalho: profissionalização dos docentes de matemática nos Sertões de Crateús.

Vários questionamentos instigaram a investigação deste programa voltado para os cursos de formação de professores: As ações do Projeto PIBID têm contribuído para melhorar a formação dos futuros professores? As ações do Projeto PIBID estão contribuindo para formação continuada dos docentes associados a esse programa? Em quais aspectos formativos, qualitativos e quantitativos o 


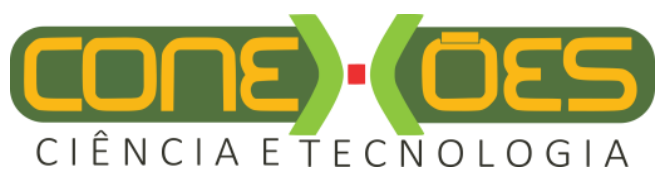

PIBID contribuem para a formação docente no curso de licenciatura em matemática e inserção no mercado de trabalho nos Sertões de Crateús?

Desencadeiam outros questionamentos, tais como: O programa, enquanto política pública contribui para diminuir os indicadores de evasão dos acadêmicos? Existe uma relação de troca de experiência entre os bolsistas e os demais acadêmicos? A relação com outros atores educacionais: "supervisores, gestores escolares, entre outros", amplia a formação inicial no sentido de percepção de novos olhares educacionais?

Ressaltando, como apresentado anteriormente, a necessidade de ampliar o campo de pesquisa na formação de professores, torna-se relevante investigar como está sendo desenvolvida a inserção no mercado de trabalho?

Considerando esse contexto histórico e a apresentação da relevância do tema, chegamos ao nosso objeto de estudo: O PIBID como política pública educacional na formação de professores. Dentro dessa pesquisa, nos propomos a analisar a formação inicial e inserção no mercado de trabalho, bem como compreender a relação de acesso, permanência e sucesso dos concludentes da licenciatura em matemática, bem como, uma análise comparativa com quem foi bolsista e os que não bolsistas, para perceber de maneira geral as contribuições do programa.

Investigar as ações desenvolvidas ao longo do PIBID do curso de Licenciatura em Matemática do IFCE, Campus Crateús, como implementação de uma política pública em educação, analisando criticamente o seu papel na formação docente inicial dos graduandos do referido curso de Licenciatura, bem como, a inserção de novos profissionais na educação.

Esperando contribuir para o entendimento dos temas da educação profissional, das políticas públicas e do desenvolvimento curricular e profissional, nosso objeto de estudo pode ser entendido como análise do PIBID enquanto divisor de águas no curso de licenciatura em matemática do IFCE- Campus Crateús e na formação profissional dos docentes nos Sertões de Crateús.

\section{METODOLOGIA/RESULTADOS}

A presente investigação insere-se em uma abordagem qualitativa e quantitativa de pesquisa, tendo em vista que reconhece a dimensão subjetiva da busca pelo conhecimento e do estabelecimento de possíveis inferências sobre os saberes de um grupo de indivíduos (SILVERMAN, 2009).
Optamos como metodologia de embasamento o Estudo de Caso (YIN, 2005), pois pretendemos investigar um fenômeno contemporâneo imerso no seu cotidiano real. Nos estudos de caso, é conveniente utilizar diferentes ferramentas de coleta de informações. $O$ autor sugere o emprego de diferentes métodos de coleta de dados, obtidos por intermédio de uma variedade de informantes, em uma diversidade de situações, e a subsequente triangulação das informações obtidas.

O IFCE, Campus Crateús representa uma totalidade única, portanto pode ser considerado como um "caso". Seus atores sociais realizam práxis que geram os currículos, num ininterrupto devir de possibilidades e concretudes. Como se não bastasse tal especificidade, os currículos formais dos mesmos vem sofrendo um recente processo de construção/modificação em sua estrutura, datada mais especificamente do ano de 2012.

Um estudo de caso pode utilizar como ferramentas questionários e entrevistas. Os questionários são econômicos em relação a tempo e dinheiro, e podem atingir um grande número de pessoas simultaneamente. Em nosso estudo de caso, nos reportamos ao Centro Controle Acadêmico (CCA) do Campus e como ferramenta de coleta de informações optamos pela aplicação de questionários com os ex-bolsistas do subprojeto de Matemática do Campus Crateús. Após a aplicação dos questionários foi realizado um diálogo entre os documentos oficiais disponibilizados pela instituição, os dados fornecidos pela CCA e as reflexões dispostas nos questionários pelos licenciandos que integraram o programa.

Outro recurso utilizado pelo presente estudo foi o contato direto com as escolas na qual os ex bolsistas atualmente lecionam através de ligações, e-mails, mensagens de texto via aplicativos de smartphones, tendo em vista que muitos trabalham e atualmente residem nos municípios limítrofes a cidade de Crateús.

Após diversas leituras do material coletado (entrevistas, questionários, documentos oficiais e dados fornecidos pelo Campus), destacaremos as concepções dos informantes e, a partir delas dialogaremos com os demais dados fornecidos. Diante dessa diversificação de informações para a construção dos resultados teóricos do presente estudo, optou-se por elencar as etapas técnicas da investigação segundo Bardin (2006), o qual se organiza em três períodos de estudos: inicialmente foi realizado, uma pré-analise, onde o principal objetivo circundou os processos sistemáticos de levantamento e organização do material a ser analisado. Nessa fase foi realizada uma análise dos documentos que norteiam as políticas públicas de formação de professores, bem como conhecer os 


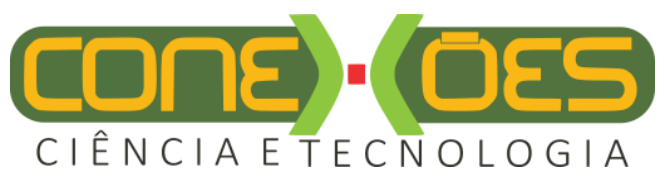

objetivos do PIBID enquanto política de elevação do magistério. Foram solicitados e posteriormente colhidos os dados do número de concludentes do curso de Licenciatura em Matemática junto com o Controle Acadêmico da instituição em consonância com a aplicação dos questionários com os exbolsistas.

E por fim foi realizada a exploração e análise dos materiais. Nessa fase foram definidas as categorias de gráficos a serem discutidos no corpo do texto e o tratamento dos resultados, inferências e interpretação, onde ocorreu simultaneamente uma condensação dos dados coletados e uma análise critica reflexiva.

Utilizamos também como aliado na análise do conteúdo a tática analítica do material "baseada em proposições teóricas” (YIN, 2005, p.133), na qual a análise e categorização dos dados primários foram feitas tendo, também, como referência os referenciais teóricos apresentados. Yin (2005) afirma que as proposições teóricas dariam "forma ao plano de coleta de dados e, por conseguinte, estabeleceriam a prioridade às estratégias analíticas relevantes" (p.133). O autor chama de "proposição" os aspectos que levaram o pesquisador ao estudo de caso, como por exemplo, as revisões feitas na literatura ou observações prévias que o investigador fez em campo.

\section{RESULTADOS E DISCUSSÃO}

A partir da análise de conteúdo segundo Bardin (2006), optamos por organizar os resultados agrupando em duas grandes temáticas, a saber: os estudantes que concluíram o curso de Licenciatura em Matemática e a sua relação com o PIBID e participação dos discentes que conseguiram concluir o curso de matemática e o PIBID.

Observamos com os dados fornecidos pela própria instituição em consonância com os documentos oficiais e relatos, infere-se uma relação direta entre os estudantes que participaram do subprojeto PIBID de Matemática e a sua continuidade e permanência a exercer o magistério. O somatório das turmas que concluíram grau até o ano de 2017 apontava que 45 (quarenta e cinco) alunos haviam se formado na licenciatura em Matemática no IFCE Campus Crateús, desse total apenas 10 (dez) não está atuando atualmente na docência, enquanto que 28 (vinte e oito) estão em sala de aula. Do total, apenas 7 (sete) licenciandos não tiveram a oportunidade de ser bolsista do subprojeto, como observado na tabela e no gráfico abaixo,
Tabela 1 - Estudantes que concluíram o curso de matemática e sua relação com o PIBID

\begin{tabular}{c|c}
\hline SITUAÇÃO & \\
\hline ATUANDO NA PROFISSÃO & 28 \\
\hline NÃO ESTÃO ATUANDO NA PROFISSÃO & 10 \\
\hline NÃO FORAM BOLSISTA DO PIBID & 7 \\
\hline TOTAL DE CONCLUDENTES & 45 \\
\hline
\end{tabular}

Fonte: IFCE, Campus Crateús (2017).

Gráfico 1 - Estudantes que concluíram o curso de matemática e sua relação com o PIBID.

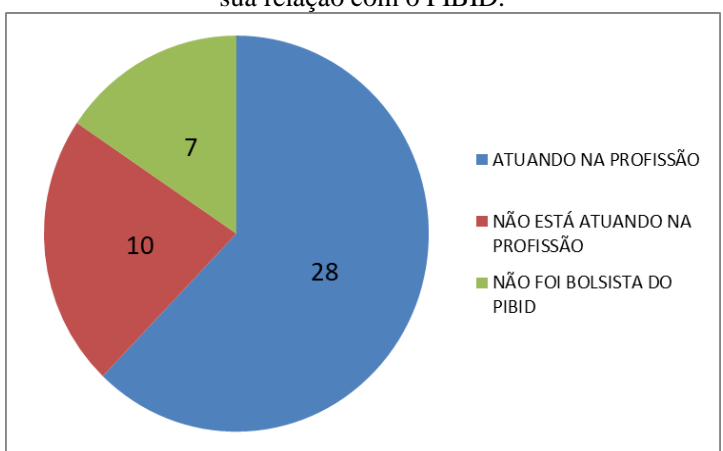

Fonte: IFCE, Campus Crateús (2017).

Os recursos visuais apresentados gráfico e tabela, configuram-se como uma opção de alternativa didática (facilitar compreensão do leitor) que nos mostram números que concerne ao subprojeto PIBID de Matemática do Campus Crateús, isso decorre do fato de que o número de concludentes do curso nos últimos anos é de 45 (quarenta e cinco) concludentes, no entanto, 38 (trinta e oito) foram bolsistas de iniciação a docência, e o mais significativo, é o resultado positivo, 28 (vinte e oito) dos pibidianos estão atuando na educação básica. Sem dúvida, atingindo um dos objetivos do PIBID, no que se refere ao ingresso no magistério e atuando na educação básica.

Tabela 2 - Participação dos discentes que concluíram o curso de matemática no PIBID.

\begin{tabular}{c|c}
\hline SITUAÇÃO & DADOS \\
\hline FORAM BOLSISTAS DO PIBID & 38 \\
\hline NÃO FORAM BOLSISTAS DO PIBID & 7 \\
\hline TOTAL DE CONCLUDENTES & 45 \\
\hline
\end{tabular}

Fonte: IFCE, Campus Crateús (2017); Relatório Capes (2017).

Dos 45 (quarenta e cinco) discentes, apenas $15,55 \%$ não tiveram a oportunidade de participar do programa. Nos permite inferir, que o motivo pelo qual 10 (dez) licenciados em Matemática que não estão atuando na profissão, visto que o programa é uma política pública tendo como um dos objetivos, que os(as) licenciando(a)s permaneçam na educação básica, que o programa de certa forma influencie na construção da identidade profissional e que esse indicador reforça ainda mais as ações do PPE (Programa de Permanência e Êxito), que busca consolidar ações, capazes de manter os estudantes 


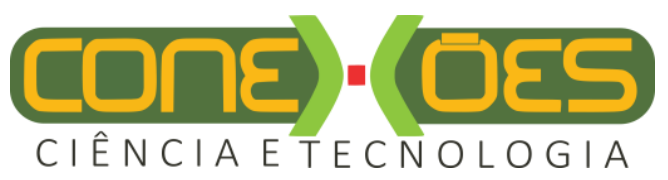

nas escolas, tanto na educação básica como no ensino superior.

É notório os impactos positivos do Programa Institucional de Bolsas de Iniciação a docência (PIBID). Percebe-se claramente que os estudantes que participaram do processo de imersão no cotidiano da sala de aula são estimulados, incentivados a permanecerem no curso. Os resultados além de qualitativos também são quantitativos, o que pode ser visualizado na tabela e no gráfico acima, Ao nos referirmos aos aspectos qualitativos destaca-se o contato com as rotinas das escolas e dos órgãos que fazem a educação. Possibilitando aos envolvidos uma aproximação direta nas escolas por meio de ações correlatas, e do constante dialogo, com os protagonistas da educação básica. Nesse cenário dinâmico e motivacional a escola funciona como um grande laboratório, dinâmico e com inúmeras possibilidades de experimentos, desafios e aprendizagens, onde os pibidianos são capazes de relacionar teoria e prática, desenvolvendo a práxis pedagógica.

Gráfico 2 - Participação dos discentes que concluíram o curso de matemática no PIBID

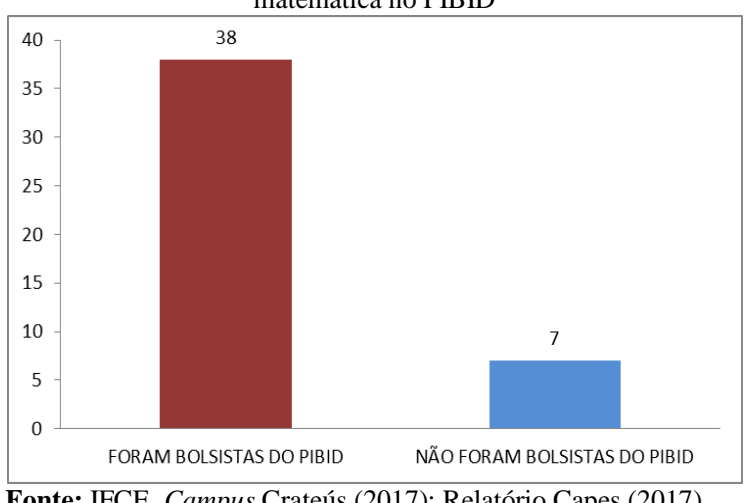

Sabemos que o desafio de formar profissionais para a carreira do magistério está sendo enfrentado de diferentes formas, o PIBID surgiu como uma alternativa para suprir inúmeras lacunas e apresentou relevância no campo da formação de professores, tendo como escopo o conhecimento docente acerca da formação, saberes, aproximação entre o "teto e o piso", (referência metáfora, para explicitar a instituição de nível superior e as escolas de educação básica), aproximar as duas instâncias educacionais como basilares na formação dos estudantes e acadêmicos, onde a escola é inserida como laboratórios das licenciaturas, e o programa PIBID, tem se constituído como a ponte mediadora das ações formativas, colaborando significativamente para a cumprir os objetivos na formação inicial docente.

É notório também que a bolsa de $\mathrm{R} \$ 400,00$ ofertada aos alunos bolsistas do programa funcionou como um incentivo, e na nossa região castigada pelas secas constantes, torna-se uma "grande fonte de renda", muitas vezes somente essa, temos alunos de diversos municípios da Região dos "Sertões de Crateús", esses por sua vez, se deslocam aproximadamente cerca de $100 \mathrm{~km}$ (cem quilômetros) diariamente, e os quatrocentos reais, além, de incentivar enquanto bolsa de iniciação, contribui significativamente como auxílio financeiro, para colaborar com inúmeras despesas.

$\mathrm{O}$ envolvimento direto com os autores e atores educacionais, com os pibidianos de iniciação a docência, como: estudantes das escolas onde os pibidianos atuaram, supervisores, coordenadores de área, gestores em geral, acaba por estabelecer uma relação comparada a uma corrente, onde cada um dos seguimentos representam elos, que só é corrente a medida que estão unidos, fortalecidos por ideias de novas perspectivas e oportunidades. Se, é na relação entre teoria e prática que consolidamos a práxis pedagógica, os pibidianos tiveram uma excelente oportunidade de exercitar os dois campos de imensa necessidade na formação dos futuros profissionais do magistério.

O que nos faz perceber que o que os números em si, já nos explicam, é que dos 48 (quarenta e oito) alunos que concluíram o curso de licenciatura em Matemática, considerado como um curso difícil da região e com grande quantitativo de evasões, apenas 7 (sete) não foram pibidianos e desse total 38 (trinta e oito) conseguiram acesso, permanência e inserção profissional, possivelmente após a experiência como pibidiano(a)s ativo(a)s e comprometido(a)s com as políticas de elevação do magistério.

Tabela 3 - Matemáticos aprovados em Mestrados exclusivamente pibidianos

\begin{tabular}{c|c}
\hline SITUAÇÃO & DADOS \\
\hline $\begin{array}{c}\text { FORAM BOSISTAS DO PIBID. } \\
\text { MARTICIPARAM DE SELEÇÕES DE } \\
\text { MESTRADO }\end{array}$ & 48 \\
\hline APROVADOS NO MESTRADO & 4
\end{tabular}

Fonte: IFCE, Campus Crateús (2017); Relatório Capes (2017).

Gráfico 3 - Matemáticos aprovados em Mestrados exclusivamente pibidianos

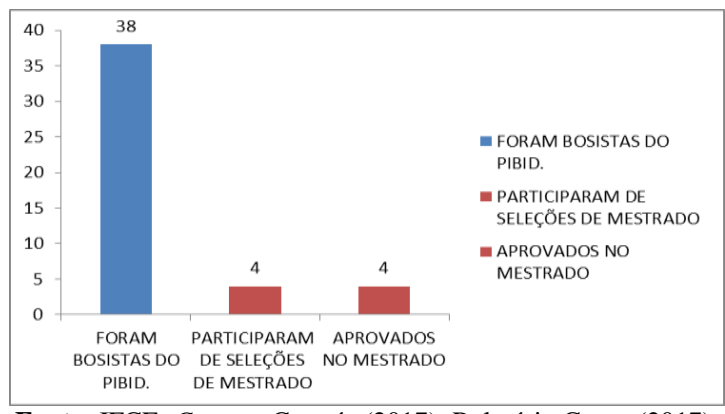

Fonte: IFCE, Campus Crateús (2017); Relatório Capes (2017) 


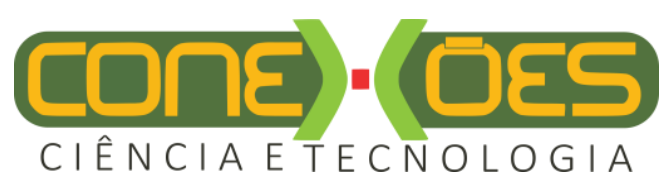

É notório os impactos positivos do programa Institucional de Iniciação a Docência (PIBID), tem proporcionado diretamente, qualitativa $\mathrm{e}$ quantitativamente aos acadêmicos do curso de licenciatura em matemática, e de forma indireta os demais envolvidos no programa. É possível inferir que os pibidianos são estudantes diferenciados, pelas inúmeras oportunidades e socialização de saberes que vão acumulando ao longo da experiência como (ID) iniciação a docência.

Avaliar é uma ação reflexiva, para uma tomada de decisão, um replanejamento e uma nova realização de outras ações, avaliar e perceber os resultados positivos, no âmbito qualitativo e quantitativo, demonstra claramente o que o gráfico acima nos proporciona de forma direta, imediata. Ao nos referimos aos aspectos qualitativos, destaca-se o contato direto com as rotinas escolares e dos órgãos que fazem a educação e comunidade educativa como um todo. Há um alinhamento entre todos os envolvidos no processo de construção dos saberes, tornando esse contato alinhado múltiplas experiências entre os pares.

Nesse cenário dinâmico e motivacional a escola de educação básica funciona como um grande laboratório vivo, e os pibidianos capazes de relacionar teorias e práticas, exercitando e desenvolvendo a práxis pedagógica.

É notório, também que a bolsa de $\mathrm{R} \$ 400,00$ (quatrocentos reais), é um grande incentivo, visto que na nossa região é castigada pelas secas constantes e sem perspectiva de outras rendas, acaba muitas vezes tornando-se a única fonte de renda do bolsista (ID). Além disso, ela promove uma experiência gerencial, em ter que se manter estudando, muitas vezes longe da família, sendo bolsista com grandes responsabilidades e com tão pouco recurso financeiro, onde na maioria das vezes a bolsa é sua única fonte de "renda".

$\mathrm{O}$ envolvimento direto com os autores sociais educacionais é uma excelente oportunidade de interação, compartilhamento de saberes e possibilidade de identificação com o magistério. Neste interim as observações, vivências, planejamento e outras atividades desenvolvidas no cenário escolar, são oportunidades favoráveis para os pibidianos em processo de iniciação.

Nesse relato explicativo os indicadores remetem a observações diretas. Dos 48 (quarenta e oito) estudantes que concluíram o curso de licenciatura em matemática, considerado por muitos como difícil e que apresenta uma carga histórica de grande evasão, apenas 7 (sete) não eram pibidianos e que os 38 (trinta e oito) dos que conseguiram êxito, desde o acesso, permanência e projeção de sucesso, foram pibidianos ativos e comprometidos com as políticas públicas.
Há menos de 10 (dez) anos, pensar em uma licenciatura pública e com área específica era algo tão distante, principalmente nessa região dos Sertões de Crateús, que está a quase $440 \mathrm{~km}$ (quatrocentos quilômetros) da capital (Fortaleza), hoje é realidade, a licenciatura, a especialização no ensino de matemática e 4 (quatro) ex. pibidianos inscritos e com $100 \%$ de aprovação em mestrados públicos, possivelmente o PIBID, foi o grande divisor de águas. Além, dos resultados apresentados quantitativamente e qualitativamente, ainda, possibilita reflexões e novos olhares, capazes de inquietar novos pesquisadores.

\section{CONSIDERAÇÕES FINAIS}

Infere-se dos relatos dos bolsistas em conjunto com análise dos dados fornecidos pela instituição que é notório as implicações, diretas que o PIBID tem na formação inicial e continuada dos licenciandos, visto que $62 \%$ (sessenta e dois porcento) continuam a exercer a profissão a qual foram habilitados. O programa além de inserir os alunos no ambiente de profissionalização docente, no caso a sala de aula, futuro local de trabalho, também lhes são apresentados metodologias e instrumentos de acordo com as realidades escolares.

Somos sabedores que avaliar implica no exercício da democracia, acompanhar as políticas públicas significa avaliar para ressignificar, Nesta compreensão a avaliação com justiça é necessária a abrangência analítica, e para tal priorizou-se as noções de contexto, processo, trajetória, pluralidade e multidimensionalidade.

Especificamente investigar as contribuições do PIBID, enquanto política pública é dar respostas de sua dimensão de seus impactos, que foram idealizados a partir de sua intencionalidade. Além disso, destacamos a necessidade contínua desse processo numa relação dialética.

Nesse processo dialético, dos resultados impactantes PIBID, no curso de licenciatura em matemática, campus Crateús - CE destacamos sua significativa relevância para sua continuidade, respaldada no êxito dos resultados obtidos na pesquisa.

Concluímos que o PIBID enquanto política pública é um divisor de águas no curso de licenciatura em matemática e na formação profissional dos docentes nos Sertões de Crateús. No entanto, ressaltamos que é necessário investir ainda mais no programa, visto que o mesmo é de fundamental importância para formação inicial e continuada de professores.

As percepções dos egressos do programa demonstram o quanto o PIBID foi relevante na 


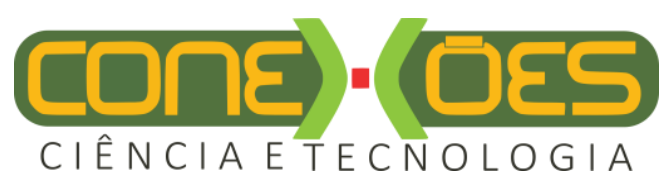

formação inicial dos professores de Matemática da cidade de Crateús. Com isso é possível, afirmar que os objetivos desse programa são de grande valia para a formação de professores, contribuindo significativamente para a formação inicial dos bolsistas de iniciação a docência, bem como, na formação continuada dos demais bolsistas envolvidos como supervisores e coordenadores de área.

\section{AGRADECIMENTOS}

Este trabalho recebeu apoio financeiro da Coordenação de Aperfeiçoamento de Pessoal de Nível Superior - Capes - Brasil.

\section{REFERÊNCIAS}

AGUIAR-JR, O. A ação do professor em sala De aula: identificando desafios Contemporâneos à prática docente. In: CUNHA, A.M.O.

Convergências e tensões no campo da formação e do trabalho docente. Livro 5. Belo Horizonte: Autêntica, 2010.

BARDIN, L. Análise de Conteúdo. Lisboa: Edições 70, 1977.

BRASIL. Plano de desenvolvimento da educação: razões, princípios e programas. Brasília, 2007. V. 4. Disponível em:

<http://portal.mec.gov.br/arquivos/pdf/livromiolov4. pdf $>$. Acesso em: 11 jan. 2018.

(b) Portaria Normativa $\mathrm{n}^{\mathrm{o}} 38$, de 12 de dezembro de 2007. Dispõe sobre o

PIBID - Programa de Bolsa Institucional de Iniciação à Docência. Diário Oficial da União. n. ${ }^{\text {o }}$ 239, de 13.12.2007, Seção 1, p. 39.

EIE - Encontro sobre Investigação na Escola, X, julho, 2010. In: Anais... Porto Alegre: Editora FURG, 2010. Disponível em: <http://www.sys.sead.furg.br/x_investigacao/index.h tml>. Acesso em: 20 ago. 2010.

ENDIPE - Encontro Nacional de Didática e Prática de Ensino, XV, abril, 2010. In: DALBEN,

FLORES, M. A. Algumas reflexões em torno da formação inicial de professores. Educação, Porto Alegre, v. 33, n. 3, p. 182-188, 2010.

GHEDIN, E. (org.) Professor reflexivo no Brasil: gênese e crítica de um conceito. 4. ed. São Paulo: Cortez, 2006, p. 17- 52.

IFCE - Instituto Federal de Educação, Ciência e Tecnologia do Ceará. Instituição, Sobre Nós. 2012.
Disponível em: <http://ifce.edu.br/sobre-oifce/sobre-nos>. Acesso em: 19 jan. 2018.

IPECE - Instituto de Pesquisa e Estratégia Econômica do Ceará. 2010. Perfil básico municipal: Crateús. Disponível em: $<$ http://www.ipece.ce.gov.br/perfil_basico_municipa 1/2010/Crateus.pdf>. Acesso em: 18 jan. 2018.

LIBÂNEO, J.C.; OLIVEIRA, J.F. de; OSCHI, M.S. Educação escolar: políticas, estrutura e organização. 6. ed. São Paulo: Cortez, 2008.

PIMENTA, S. G. Professor Reflexivo: construindo uma crítica. In: PIMENTA, S.G.;

SILVERMAN, D. Interpretação de dados qualitativos: métodos para análise de entrevistas, textos e interações. Porto Alegre: Artmed, 2009.

YIN, R. K. Estudo de caso: planejamento e métodos. (Trad. Daniel Grassi). 3. ed. Porto Alegre: Bookman, 2005. 